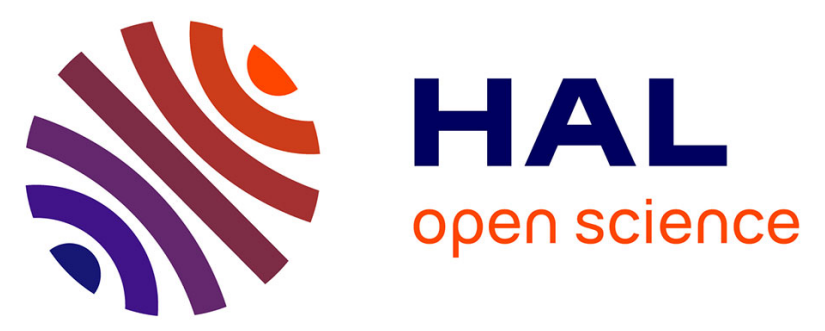

\title{
Characterization of the interface reaction zone between iron and NiZn ferrite in a composite material - Study of a silica layer as a diffusion barrier
}

Rudy Guicheteau, Jean-Louis Bobet, Miyasaki Takamichi, Akira Kawasaki, Yongfeng Lu, Jean-François Silvain

\section{To cite this version:}

Rudy Guicheteau, Jean-Louis Bobet, Miyasaki Takamichi, Akira Kawasaki, Yongfeng Lu, et al.. Characterization of the interface reaction zone between iron and NiZn ferrite in a composite material Study of a silica layer as a diffusion barrier. Journal of Alloys and Compounds, 2017, 724, pp.711-719. 10.1016/j.jallcom.2017.06.255 . hal-01622902

\section{HAL Id: hal-01622902 https://hal.science/hal-01622902}

Submitted on 15 Sep 2020

HAL is a multi-disciplinary open access archive for the deposit and dissemination of scientific research documents, whether they are published or not. The documents may come from teaching and research institutions in France or abroad, or from public or private research centers.
L'archive ouverte pluridisciplinaire HAL, est destinée au dépôt et à la diffusion de documents scientifiques de niveau recherche, publiés ou non, émanant des établissements d'enseignement et de recherche français ou étrangers, des laboratoires publics ou privés. 


\title{
Characterization of the interface reaction zone between iron and NiZn ferrite in a composite material - Study of a silica layer as a diffusion barrier
}

\author{
Rudy Guicheteau a , Jean-Louis Bobet a , Takamichi Miyasaki ${ }^{\mathrm{b}}$, Akira Kawasaki ${ }^{\mathrm{c}}$, \\ Yongfeng $\mathrm{Lu}^{\mathrm{d}}$, Jean-François Silvain ${ }^{\mathrm{a}, \mathrm{d}, *}$ \\ a CNRS, Univ. Bordeaux, ICMCB, UPR 9048, F-33600, Pessac, France \\ ${ }^{\mathrm{b}}$ Department of Material Processing, Graduate School of Engineering, Tohoku University, Sendai, 980-8779, Japan \\ c Technical Division, School of Engineering, Tohoku University, Sendai, 980-8579, Japan \\ d Department of Electrical and Computer Engineering, University of Nebraska-Lincoln, Lincoln, NE, 68588-0511, USA
}

\section{Keywords:}

Composite materials

Ferrite

Iron

Interface

Redox reaction

\begin{abstract}
A B S T R A C T
Iron ferrite composites fabricated by powder metallurgy processes were studied for electromagnetic and large band microwave absorption applications. The sintering behavior of such composites is not well understood, and these materials have been found to lose their magnetic properties or mechanical properties. Different systems of Fe/NiZn ferrite composites were investigated in order to better under stand the chemical reactions that occur between oxide spinel and iron particles during the fabrication process. Three different systems, two models and one reference material were studied to analyze the chemical reactions in the aforementioned fabrication process. The first model consisted of iron films deposited by Physical Vapor Deposition (PVD) onto an NiZn ferrite substrate. The reference material was made of a mixture of hot pressed iron and ferrite powders. In the second model, a $\mathrm{SiO}_{2}$ layer was deposited by PVD onto the NiZn ferrite substrate, followed by iron deposition by PVD to study the role of $\mathrm{SiO}_{2}$ as a diffusion barrier. The materials were characterized using scanning electron microscopy (SEM), transmission electron microscopy (TEM), dilatometry, electron probe microscopy analysis (EPMA) and X ray diffraction (XRD). For the Fe/NiZn ferrite systems, the experimental results showed (i) an oxido reduction reaction above $600{ }^{\circ} \mathrm{C}$ that produced $\mathrm{FeO}$ and $\mathrm{Fe}_{\mathrm{x}} \mathrm{Ni}_{1-\mathrm{x}}$ phases and (ii) a diffusion process of $\mathrm{Ni}$ and $\mathrm{Zn}$. The combination of diffusion and oxido reduction reaction induced the total consumption of the initial phase and a considerable decrease in magnetic properties. By adding a silica layer between the iron and ferrite layers, the redox interfacial reaction and iron diffusion were prevented at temperatures up to $800{ }^{\circ} \mathrm{C}$.
\end{abstract}

\section{Introduction}

In recent decades, the development of bulk single phase mag netic materials has mainly focused on the optimization of com posites or nanocomposite materials. These materials are being increasingly investigated for their electromagnetic properties in transformers [1], generators, motors [2], magnetic amplifiers and microwave absorbers [3,4]. Different types of organic [5-7] and inorganic [8] composites are already available. Composites contain

\footnotetext{
* Corresponding author. ICMCB-CNRS, 87 avenue du Dr Albert Schweitzer, 33608, Pessac Cedex, France.

E-mail address: jean-francois.silvain@icmcb.cnrs.fr (J.-F. Silvain).
}

one component with good magnetic properties, while the other is either an insulator [5] and/or a binder [6]. Due to the presence of a non magnetic element, the global magnetic properties (e.g. the permittivity) of the whole composite system decreases. To over come the loss of magnetic properties in the composite, using a soft magnetic material such as Fe or an Fe alloy and soft ferrite [3,4,9-11] instead of a non magnetic material has been investi gated. The magnetic Fe or Fe alloy systems have been reported to have high (i) initial permeability and (ii) saturation magnetization. Owing to their low electrical resistivity and Eddy current losses, they cannot be used at high frequency. On the other hand, soft ferrite allows their usage at high frequencies due to their high electrical resistivity, high permeability, low density and low 


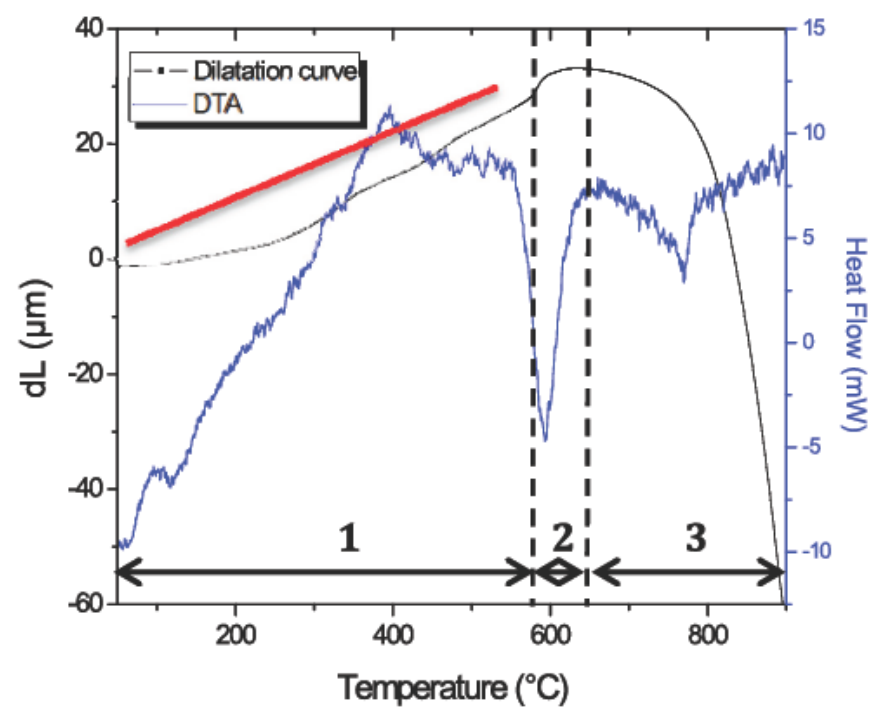

Fig. 1. Dilatation and DTA curves of Fe-Ferrite mixed powders during sintering process (the red straight line is the theoretical line of pure iron powders for a matter of comparison). (For interpretation of the references to colour in this figure legend, the reader is referred to the web version of this article.)

magnetization saturation. Combining Fe with soft ferrite would allow for using them in a large frequency range for electromagnetic applications and in large band of microwave absorption. Fe, Fe al loys and ferrites are sintered at a high temperature (above $1000^{\circ} \mathrm{C}$ ), whereas composites are sintered at a temperature lower than $700{ }^{\circ} \mathrm{C}$. It can be noted from the literature [12] that composites sintered at temperatures below $700{ }^{\circ} \mathrm{C}$ possess poor mechanical properties. The current state of art of these composites with respect to their sintering behavior has hindered the development of these materials.

In the present work, microstructural and chemical analyses of the iron ferrite interfacial zones were studied in correlation to their fabrication and post treatment processes. The first model system consists of a bulk polished ferrite substrate covered by an iron thin film using physical vapor deposition (PVD). The main phase consisted of ferrite; such a system provides the ability to study the iron diffusion into ferrite. In the second system, NiZn ferrite and iron particles were mixed and densified, leading to the formation of a ferrite/Fe composite. In the second system, iron was present as the major phase. A chemical reaction between both species at a tem perature above $700^{\circ} \mathrm{C}$ was highlighted. In the third system (i.e. the second model), an $\mathrm{SiO}_{2}$ thin layer was first sputter deposited on top of the ferrite bulk substrate, followed by PVD of an iron film in order to prevent the above reaction and to allow sintering of the com posite at higher temperatures. The goal of this study was to establish what type of material should be used to present the highest electromagnetic properties and sufficient mechanical strength (to allow easy handling of the material).

\section{Experimental}

\subsection{Ferrite iron deposited film (model material)}

$\mathrm{ZnO}, \mathrm{NiO}$ and $\mathrm{Fe}_{2} \mathrm{O}_{3}$, (Alpha Aesar, 99\%) powders were ball milled using a Fritsch pulverisette 5 planetary ball mill. The pa rameters used for ball milling were as follows: $2 \mathrm{~h}$ ball milling duration with a ratio mass ball $_{\text {/ }}$ mass $_{\text {powder }} 12$ and a rotation speed of $200 \mathrm{rpm}$. Ball milled powders were then compressed as pellets under a pressure of $50 \mathrm{MPa}$. Then, the compressed pellets were sintered for $20 \mathrm{~h}$ at $1300^{\circ} \mathrm{C}$ under an air atmosphere to allow grain growth of $\mathrm{Ni}_{0.5} \mathrm{Zn}_{0.5} \mathrm{Fe}_{2} \mathrm{O}_{4}$ dense ferrite substrates. Slices of ferrite substrates $\left(20 \times 1 \mathrm{~mm}^{2}\right)$ were obtained by cutting and polishing the pellets. The average surface roughness of these substrates, measured by a laser profilometer, was about $300 \mathrm{~nm}$. Iron thin films, of $1 \mu \mathrm{m}$ thickness, were deposited on ferrite substrates by magnetron sputtering using Plassys MP700 equipment. The deposition was performed for $200 \mathrm{~min}$ at $250 \mathrm{~W}$ and $5 \mathrm{~Pa}$ Argon pressure with a $7.62 \mathrm{~cm}$ diameter iron target.

\subsection{Mixed powder pellets (reference material)}

Pure iron powders with particles size ranging from 10 to $40 \mu \mathrm{m}$ obtained by gas atomization were used (Goodfellow, 99.9\%) to make pellets. Parts of the pellets obtained in Section 2.1 were then crushed manually in an agate mortar for about 20 min to obtain

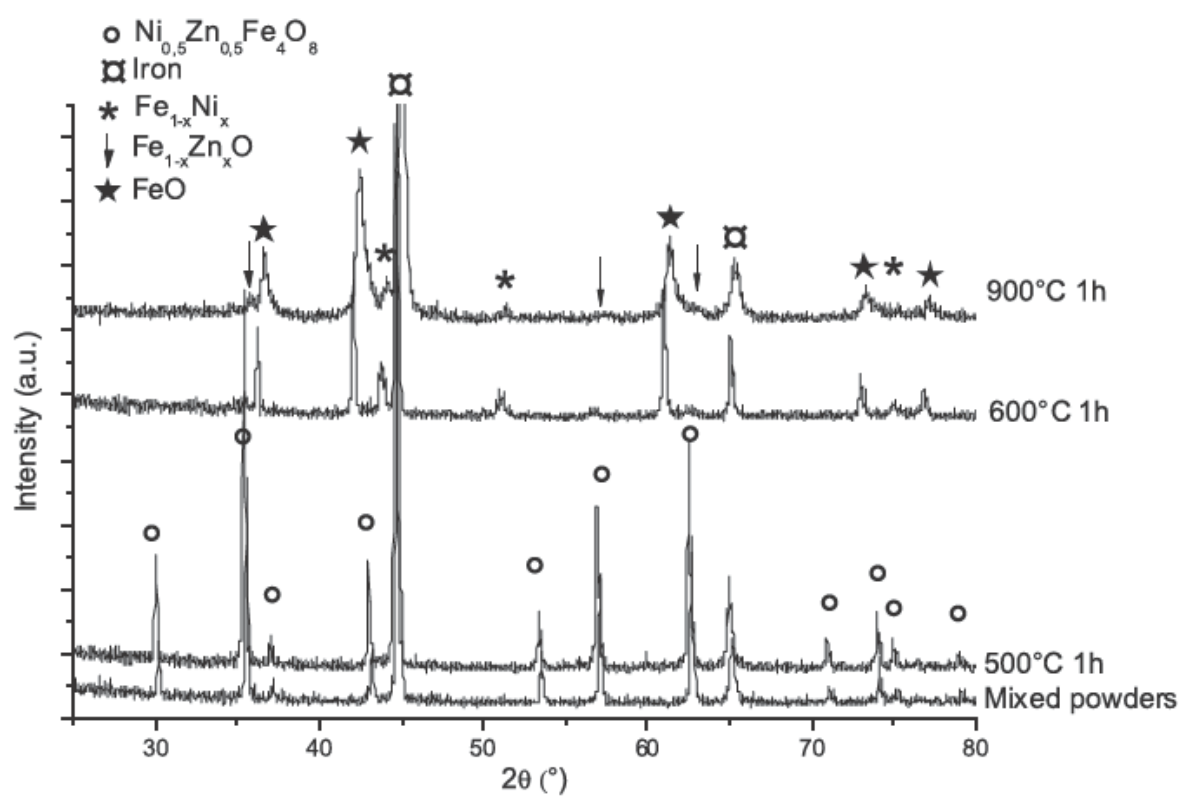

Fig. 2. XRD analysis of the Iron-Ferrite mixed powder system after different heat treatment. 
$\mathrm{Ni}_{0.5} \mathrm{Zn}_{05} \mathrm{Fe}_{2} \mathrm{O}_{4}$ ferrite particle size of $30 \mu \mathrm{m}$. Mixtures of iron $+20 \mathrm{wt} \%$ of ferrite particles were prepared and cold pressed at $400 \mathrm{MPa}$. X ray diffraction (XRD) pattern of the mixed powder before sintering shows the presence of pure ferrite phase with no extra peaks. The final pellet dimensions obtained were $20 \mathrm{~mm}$ in diameter and $2 \mathrm{~mm}$ in thickness.

\subsection{Ferrite silica iron deposited film (model material)}

Silica thin films about $70 \mathrm{~nm}$ thick were deposited by magne tron sputtering, on the polished slide of the ferrite substrate heated at $500{ }^{\circ} \mathrm{C}$ (see Section 2.1). The deposition was performed at $50 \mathrm{~W}$ under $5 \mathrm{~Pa}$ of Argon pressure, with a 3 inch diameter silica target, for $15 \mathrm{~min}$. An iron thin film $1 \mu \mathrm{m}$ thick was then deposited on the silica layer by magnetron sputtering with the same process described in Section 2.1.

\subsection{Heat treatment}

Both model systems were heat treated at $500{ }^{\circ} \mathrm{C}, 650{ }^{\circ} \mathrm{C}, 700{ }^{\circ} \mathrm{C}$ and $900{ }^{\circ} \mathrm{C}$ for $1 \mathrm{~h}$, under an inert atmosphere of purified $\mathrm{N}_{2}$, in a tubular furnace at a heating rate of $10{ }^{\circ} \mathrm{C} / \mathrm{min}$. Microstructural characterizations were performed using a scanning electron mi croscope (SEM, TESCAN Vega $3 \mathrm{SB}$ ) and a high resolution trans mission electron microscope (HR TEM, HF 200EDX, Hitachi). For TEM analysis, $\mathrm{Fe} \mathrm{SiO}_{2}$ ferrite thin films were prepared using con ventional ion milling method (GATAN PIPS Model 691, Gatan Inc.). Elemental analyses were performed using an electron probe microanalyzer (Cameca SX 100) equipped with three WDS (wave length dispersive spectroscopy) and one SDD (silicon drift detector) spectroscope. X Ray diffraction (XRD) was performed using a Phi lips PANalytical X'Pert (PW1820) diffractometer with $\mathrm{Cu} \mathrm{K}_{\alpha} 1$ radiation.

\section{Results}

\subsection{Reference iron/ferrite material}

The sintering behavior of the Fe/ferrite composite was analyzed. The variation of the sample length (left part of the $y$ axis) and of the heat flow (right part of the y axis) versus the heating temperature ( $x$ axis) is presented in Fig. 1. From the variation of the sample length with temperature, three temperature ranges, correlated with three material behaviors, can be defined as follows:

1. From room temperature to $580{ }^{\circ} \mathrm{C}$, an almost linear increase of the sample length was observed and compared with the varia tion of pure iron powders (red line). As both curves were very close, this linear increase can be mainly attributed to the ther mal expansion of the iron part of the Fe/ferrite mixed powder materials. In this temperature range chosen, a small and rather broad exothermic peak was observed. It can be attributed to an increase of the ferrite crystallites size that may be previously reduced during the crushing of the pellet Ferrite materials. This hypothesis was well supported by the XRD pattern analysis of the mixed $\mathrm{Fe} /$ Ferrite powders after a heat treatment at $500{ }^{\circ} \mathrm{C}$ (Fig. $2500{ }^{\circ} \mathrm{C}$ ). Indeed, XRD analysis does not show any addi tional phase (compared with the XRD pattern of mixed pow ders) but highlights a decrease in the full width at half maximum (FWHM) of the peaks of the ferrite phase. SEM mi crographs (Fig. 3a) of typical Fe/ferrite show the absence of a reaction zone between the ferrite and the Fe powders.

2. From $580{ }^{\circ} \mathrm{C}$ to $650{ }^{\circ} \mathrm{C}$, the variation in the sample length was almost negligible. In this temperature range, the dilatation of the composite material was counterbalanced by the contraction of the material associated with the beginning of the sintering process. An intense endothermic peak (Fig. 1) was observed in the temperature range studied. This endothermic peak may be associated with the transformation of the ferrite phase into three new components: $\mathrm{FeO}, \mathrm{Fe}_{1-\mathrm{x}} \mathrm{Ni}_{\mathrm{x}}$ and $\mathrm{Fe}_{1-\mathrm{x}} \mathrm{Zn} \mathrm{n}_{\mathrm{x}} \mathrm{O}$, as shown in the XRD pattern taken at $600{ }^{\circ} \mathrm{C}$ (Fig. $2600{ }^{\circ} \mathrm{C}$ ). After annealing at $700{ }^{\circ} \mathrm{C}$, a reaction zone almost $6 \mu \mathrm{m}$ in depth composed of white stripes and dots was present at the ferrite Fe interface (see SEM micrograph in Fig. 3b) in contrast to samples annealed at $500{ }^{\circ} \mathrm{C}$. The exact composition of the reaction zone was not confirmed, but could be associated with the initial transformation of the ferrite phase with temperature.

3. Above $650{ }^{\circ} \mathrm{C}$, a sharp decrease in the sample length was observed. This decrease has to be attributed to the sintering of the mixed powder materials. In this temperature range, a small endothermic peak, at $760{ }^{\circ} \mathrm{C}$ was observed and may be attrib uted to sublimation of the $\mathrm{Zn}$ species. At these temperatures, the ferrite phase is fully transformed into $\mathrm{FeO}, \mathrm{Fe}_{1-\mathrm{x}} \mathrm{Ni}_{\mathrm{x}}$ and $\mathrm{Fe}_{1-}$ ${ }_{x} \mathrm{Zn}_{\mathrm{x}} \mathrm{O}$, as shown in the XRD patterns recorded after heating
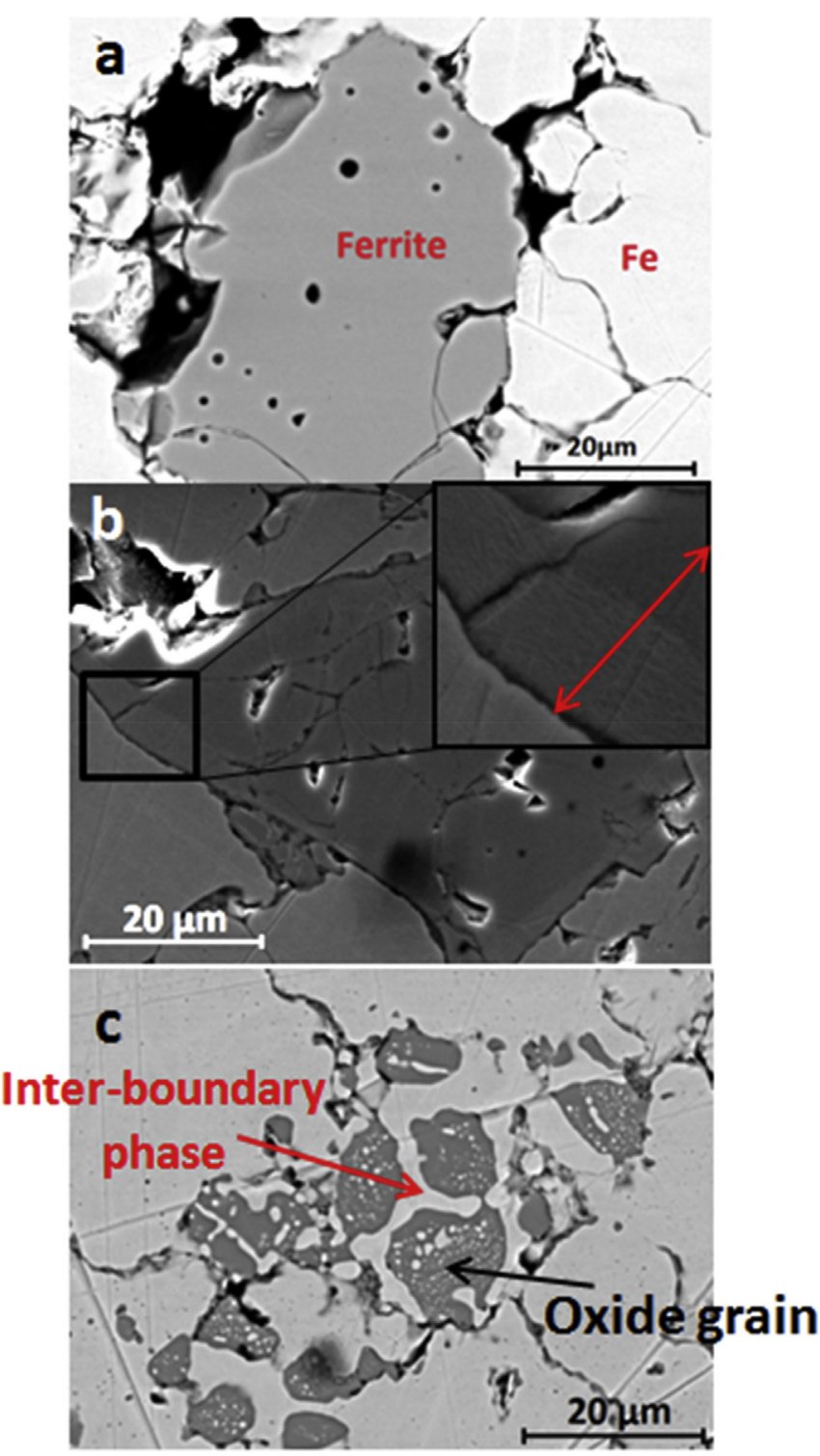

Fig. 3. SEM micrographs of Fe-Ferrite mixed powders, heat treated at (a) $500{ }^{\circ} \mathrm{C}$, (b) $700{ }^{\circ} \mathrm{C}$ and (c) $900{ }^{\circ} \mathrm{C}$ (BSE mode). 


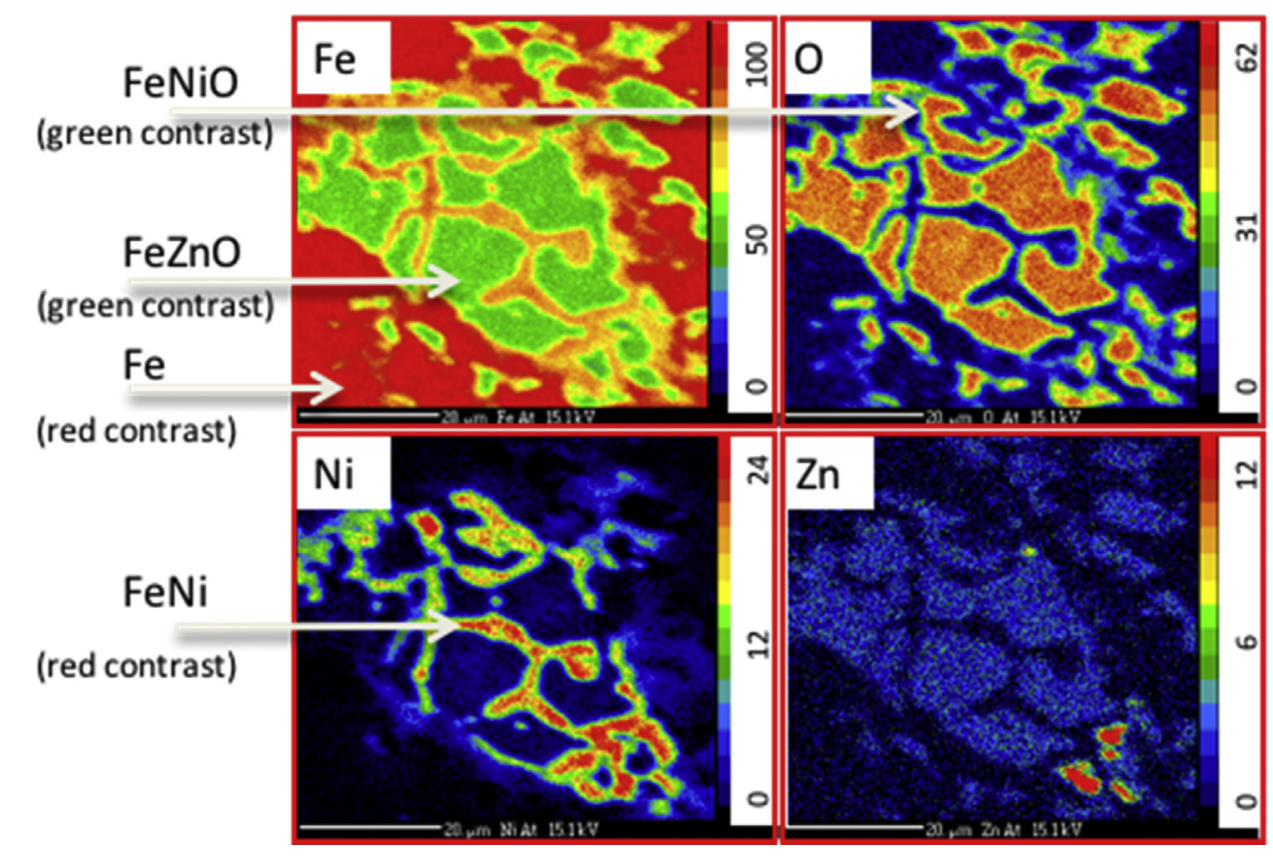

Fig. 4. EPMA element cartography of $\mathrm{Fe}, \mathrm{Ni}, \mathrm{O}, \mathrm{Zn}$ on ferrite mixed powders after treatment at $900{ }^{\circ} \mathrm{C}$ under $\mathrm{N}_{2}$.

the samples at $900{ }^{\circ} \mathrm{C}$ (Fig. $2900{ }^{\circ} \mathrm{C}$ ). Fig. 3c shows a typical micrograph of such materials where pure Fe grains were still present and associated with a complex microstructure of the three new phases. EPMA elemental analyses are presented in Fig. 4. The oxygen (O), iron (Fe), nickel ( $\mathrm{Ni}$ ) and zinc ( $\mathrm{Zn})$ EPMA maps clearly show four different areas. The color code on the right of the maps is associated with the relative atomic content of the element going from dark blue (minimum value) to red (maximum value). It must be inferred that, for the four elemental maps, this minimum and maximum values are different for the four maps (see number on the right of the atomic content color code). Three phases were detected by XRD analysis (i.e. pure $\mathrm{Fe}, \mathrm{Fe}_{1-\mathrm{x}} \mathrm{Ni}_{\mathrm{x}}$, FeZnO). The fourth one, which can be attributed to the FeNiO phase, was present at the boundary between $\mathrm{Fe}_{1-\mathrm{x}} \mathrm{Ni}_{\mathrm{x}}$ and $\mathrm{FeZnO}$ (green contrast in the oxygen map). This phase could not be detected by XRD due to its low content and poor crystallinity.

\subsection{Model ferrite iron material}

The Fe/ferrite composite materials fabricated by powder met allurgy with Fe and ferrite powders, with a PVD iron thin film deposited onto polish bulk ferrite substrate, were annealed under $A$ controlled atmosphere $\left(\mathrm{N}_{2}\right)$ at three different temperatures (i.e. $500{ }^{\circ} \mathrm{C}, 700{ }^{\circ} \mathrm{C}$ and $900{ }^{\circ} \mathrm{C}$ ). SEM microstructures and corre sponding EDS elemental maps were recorded for the three annealing temperatures.

Fig. 5 presents the typical SEM cross section microstructures recorded on polished samples. Fig. 5a shows that, up to $500{ }^{\circ} \mathrm{C}$, no evolution of the microstructure or chemical interfacial reaction between the iron film and the ferrite substrate was observed. On the contrary, for the Fe/ferrite composite materials, chemical interfacial reactions were easily observed at higher annealing temperatures (Fig. $5 \mathrm{~b}$ for $700^{\circ} \mathrm{C}$ and Fig. $5 \mathrm{c}$ for $900^{\circ} \mathrm{C}$ ). As expected, the thickness of these complex reaction zones increased with the annealing temperature, from about $14 \mu \mathrm{m}$ (at $700{ }^{\circ} \mathrm{C}$ ) to nearly $36 \mu \mathrm{m}\left(\right.$ at $\left.900^{\circ} \mathrm{C}\right)$. At $700{ }^{\circ} \mathrm{C}$, the interfacial reaction zone can be divided into two distinct parts from the iron surface to the ferrite bulk: (i) the first one, called d1 in Fig. 5b (thickness close to $6 \mu \mathrm{m}$ ) with white stripes SEM contrasts and (ii) the second one, called d2 in Fig. 5b (thickness close to $8 \mu \mathrm{m}$ ) with homogeneously distributed white dots. EDS elemental cartography of the typical diffusion zone can be seen in Fig. 6, which includes both an SEM micrograph and the $\mathrm{Fe}, \mathrm{O}$, Ni and $\mathrm{Zn}$ elemental maps. As for Fig. 4, the atomic content of the four maps, which can be associated with the color map, has to be visualized on the right side of each elemental maps. Dashed blue and red lines on the SEM micrograph and EPMA maps (Fig. 6) correspond to the initial iron film (1 $\mu \mathrm{m}$ thick) and the

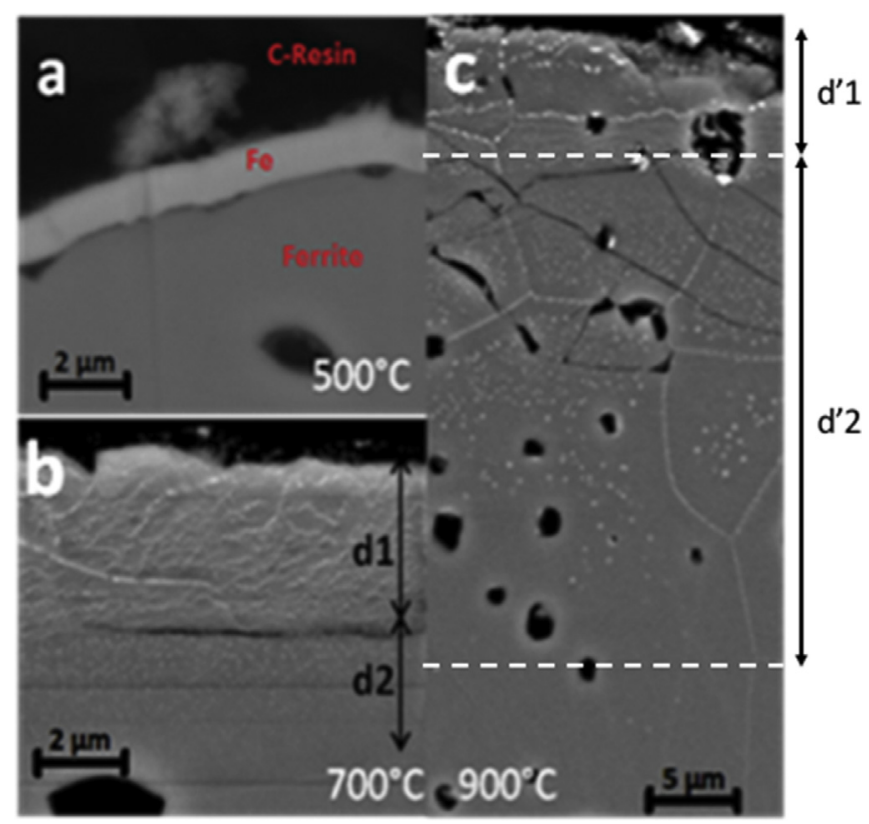

Fig. 5. Cross section SEM micrograph (BSE mode) of (a) non-annealed PVD Fe-Ferrite materials (b) $700{ }^{\circ} \mathrm{C}$ heat treatment material and (c) $900{ }^{\circ} \mathrm{C}$ heat treatment material. 


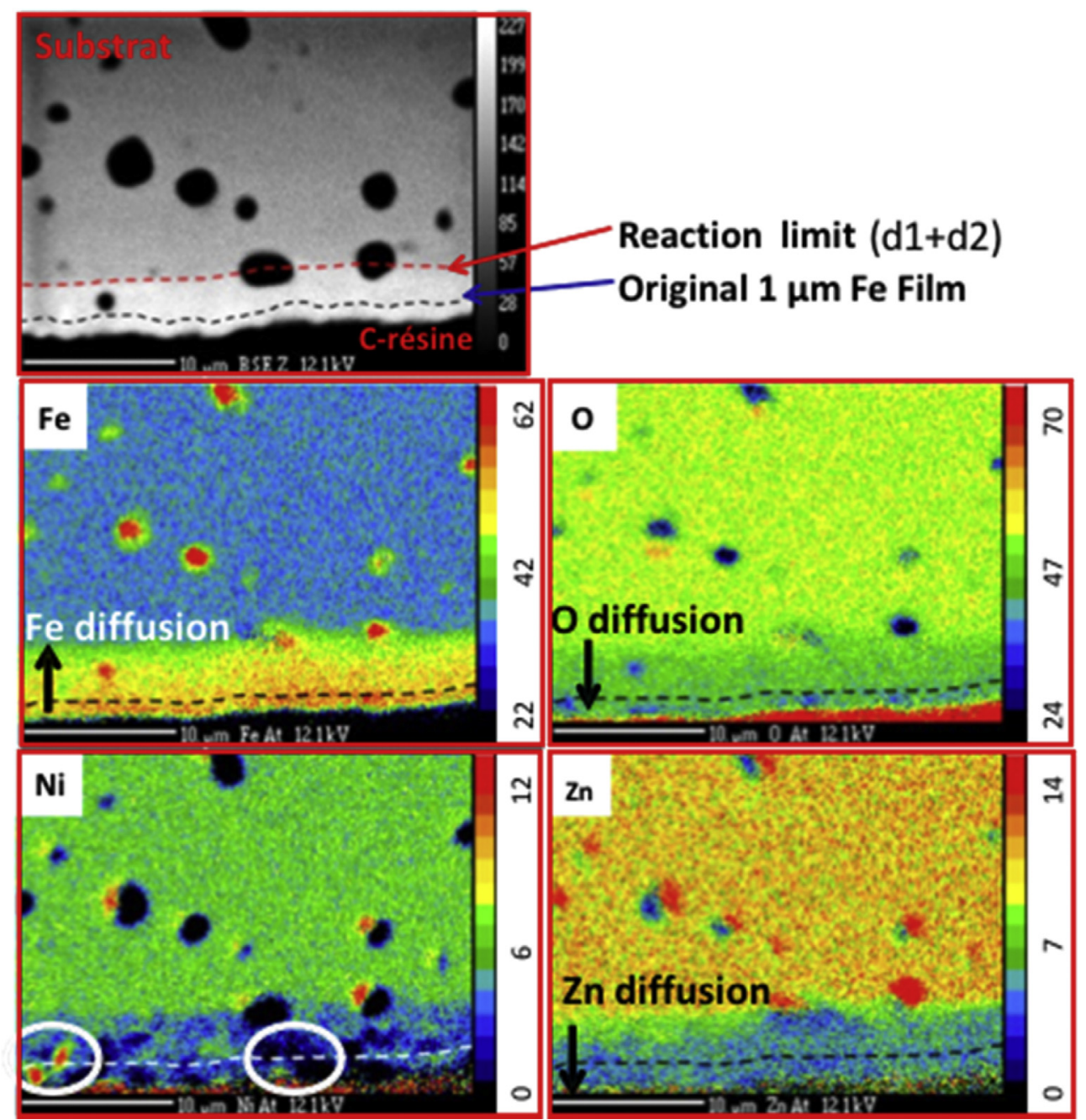

Fig. 6. SEM micrograph and corresponding EPMA element cartography of Fe, Ni, O, Zn on Fe-ferrite film after heat treatment at $700{ }^{\circ} \mathrm{C}$ under $\mathrm{N}_{2}$.

diffusion zone analyzed with the elemental maps corresponding to the $\mathrm{d} 1$ zone (close to $6 \mu \mathrm{m}$ ) (Fig. 5b), respectively. It has to be mentioned that the black circular contrast, visible on the SEM mi crographs, was associated with porosities. In the $6 \mu \mathrm{m}$ diffusion zone, the oxygen and zinc contents were close to 40 and 5 at. \%, respectively. The low oxygen and zinc atomic concentrations compared with the bulk (50 and 10 at. \%) shows that oxygen and zinc diffused homogeneously during the heat treatment from the ferrite bulk substrate toward the PVD iron layer. This diffusion process may be associated with the reverse diffusion of iron and the depletion of nickel.

At $900{ }^{\circ} \mathrm{C}$, the $\mathrm{d}^{\prime} 1$ zone was detected (Fig. 5c) and associated with the $\mathrm{d}^{\prime} 2$ zone (thickness close to $30 \mu \mathrm{m}$ ). The elemental atomic concentration of this $\mathrm{d}^{\prime} 1$ zone, presented in Fig. 7, is very close to that of the $\mathrm{d} 1$ zone observed after annealing at $700{ }^{\circ} \mathrm{C}$. However, inside the $\mathrm{d}^{\prime} 2$ zone, an evolution of the elemental composition of the ferrite grain boundaries was observed. Indeed, a depletion of iron associated with the enrichment of both nickel and zinc was clearly visible. As for Fig. 4, the atomic content of the four maps, which can be associated with the color map, can be visualized on the right side of each elemental map.

\subsection{Model ferrite $\mathrm{SiO}_{2}$ iron material}

In order to kinetically reduce the chemical reaction that occurred above $500{ }^{\circ} \mathrm{C}$ between iron and ferrite during annealing, an interphase layer was intercalated between Fe and ferrite. From the literature $[13,14]$, it was established that silica is chemically inert towards iron and magnetite at temperature up to $900{ }^{\circ} \mathrm{C}$ under a controlled atmosphere $\left(\mathrm{N}_{2}\right)$. Hence, from these previous results, $\mathrm{SiO}_{2}$ thin films (thickness close to $50 \mathrm{~nm}$ ) were PVD deposited onto the polished ferrite substrate prior to PVD iron film deposition. One hour heat treatments were then performed at $700{ }^{\circ} \mathrm{C}$ and $900{ }^{\circ} \mathrm{C}$, under an $\mathrm{N}_{2}$ atmosphere, on PVD Fe PVD $\mathrm{SiO}_{2}$ ferrite multilayer materials.

Fig. 8 shows SEM (Fig. 8a) and TEM (Fig. 8b) cross sectional micrographs of the multilayer material annealed at $700{ }^{\circ} \mathrm{C}$ for $1 \mathrm{~h}$. Both SEM and TEM micrographs clearly demonstrate that the $\mathrm{SiO}_{2}$ thin film had not chemically reacted with either iron or ferrite during the annealing process. In Fig. 8b, nano diffraction patterns recorded from ferrite, $\mathrm{SiO}_{2}$ and iron are shown. The indexations of these diffraction patterns was done using the space group and lattice parameter of each phase (e.g. ferrite: S.G. Fd $3 \mathrm{~m}$ with a $\quad 8.40 \AA \mathrm{SiO}_{2}$ : amorphous and Fe: S.G. Im $3 \mathrm{~m}$ with a $2.89 \AA$ ).

In contrast to the behavior of the multilayer material annealed at $700{ }^{\circ} \mathrm{C}$, annealing at $900{ }^{\circ} \mathrm{C}$ clearly shows that a chemical reac tion had occurred (see Fig. 9a (SEM micrograph) and 9b (TEM micrograph)). Indeed, both SEM and TEM analyses show that the entire Fe film had diffused inside the ferrite substrate, through the $\mathrm{SiO}_{2}$ layer, leading to the formation of a thin $\mathrm{Fe}_{2} \mathrm{SiO}_{4}$ layer (fayalite: 


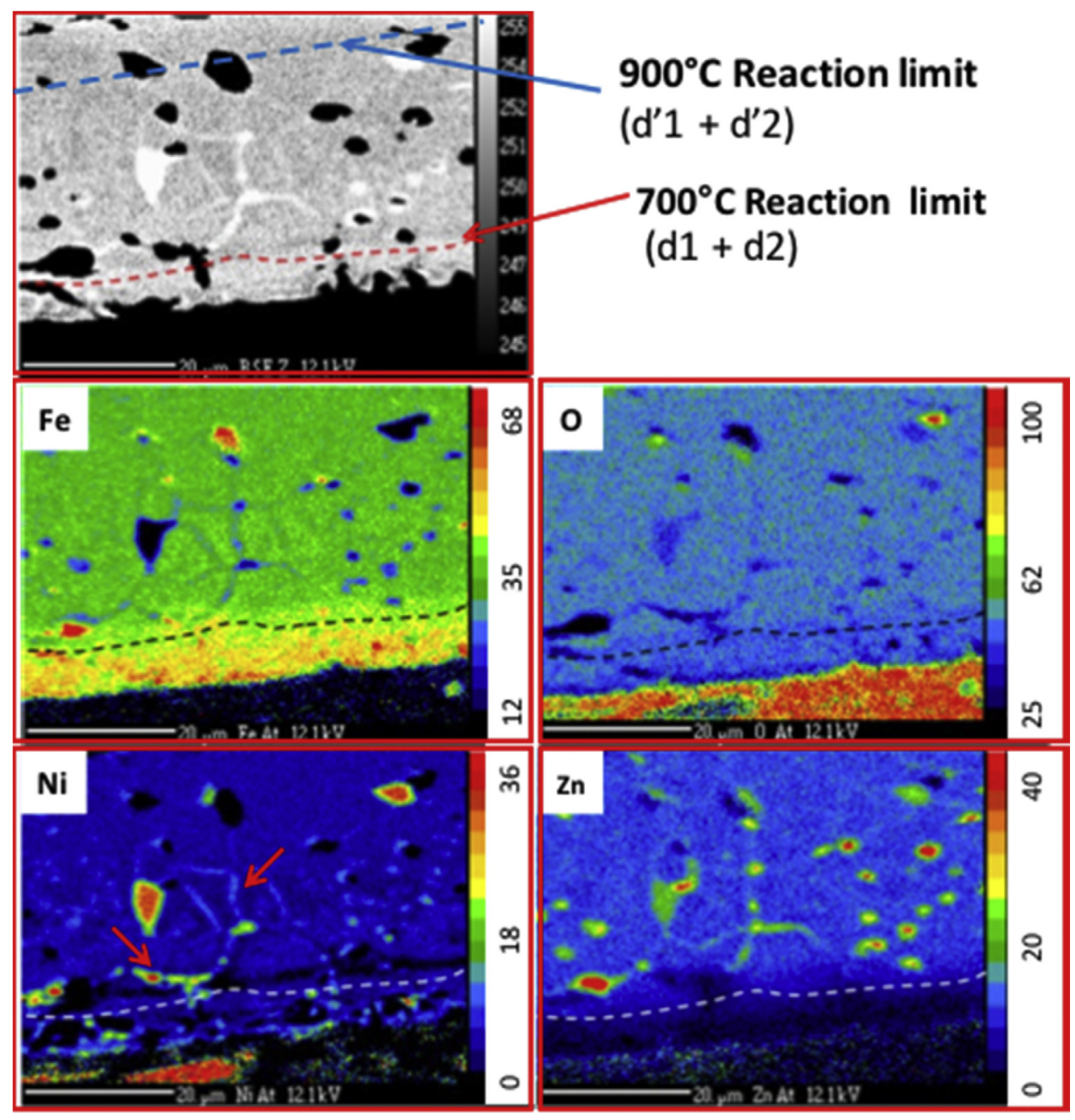

Fig. 7. SEM micrograph and corresponding EPMA element cartography of $\mathrm{Fe}, \mathrm{Ni}, \mathrm{O}, \mathrm{Zn}$ on Fe-ferrite film after heat treatment at $900{ }^{\circ} \mathrm{C}$ under $\mathrm{N}_{2}$.

S.G. Pbnm with a $\quad 4.76 \AA$, b $\quad 10.20 \AA ̊$ and c $5.98 \AA$ ).

\section{Discussion}

The Ni Fe O ternary phase diagram [15] indicates that, at $1000{ }^{\circ} \mathrm{C}$, $\mathrm{Ni}$ and $\mathrm{FeO}$ (with higher $\mathrm{FeO}$ content) are not chemically stable and react to form an $\mathrm{FeNi} \mathrm{FeO}$ solid solution. Our results show that a redox reaction occurs above $600{ }^{\circ} \mathrm{C}$. The reaction zone (shown by dotted line Figs. 6 and 7) was similar (about $13 \mu \mathrm{m}$ ) after heat treatment at $700{ }^{\circ} \mathrm{C}$ or $900{ }^{\circ} \mathrm{C}$. Moreover, at $900{ }^{\circ} \mathrm{C}$, the oxygen content was almost constant throughout the sample (around $45 \%$ ). It is then possible to infer that such diffusion was limited by the redox reaction and by the diffusion of iron in the ferrite, forming the $\mathrm{Fe}(\mathrm{Zn}) \mathrm{O}$ phase highlighted by XRD.

Therefore, after heat treatment at $900{ }^{\circ} \mathrm{C}$, there was no zinc into the reaction zone and in the two model systems, there was segre gation of nickel at the grain boundaries.

From the abovementioned results, we can suggest the following mechanism (cf. Fig. 10):

Metallic iron $\left(\mathrm{Fe}^{0}\right)$ is oxidized by iron (III) and nickel (II) to form iron (II) and metal nickel according to the following reactions:

$\mathrm{Ni}^{2+}+\mathrm{Fe}_{(\mathrm{s})}^{0} \leftrightarrow \mathrm{Fe}^{2+}+\mathrm{Ni}_{(\mathrm{s})}^{0}$
$2 \mathrm{Fe}^{3+}+\mathrm{Fe}_{(\mathrm{s})}^{0} \leftrightarrow 3 \mathrm{Fe}^{2+}$

This oxidation can be correlated with the exothermic peak starting around $580{ }^{\circ} \mathrm{C}$ (reported on Fig. 1). This reaction leads to the formation of $\mathrm{FeO}$ and $\mathrm{ZnO}$ phases. Moreover, the $\mathrm{Zn} \mathrm{Fe} \mathrm{O}$ ternary phase diagram [16] indicates the high stability of both $\mathrm{FeO}$ and $\mathrm{ZnO}$. The possible formation of a $\mathrm{Fe}(\mathrm{Zn}) \mathrm{O}$ solid solution (cf. Fig. 10a) has also been reported.

Metallic iron diffuses through the FeO phase to form an $\mathrm{Fe}_{1-\mathrm{x}} \mathrm{Ni}_{\mathrm{x}}$ (cf. Fig. 10b) solid solution.

A redox reaction takes places with two possible results:

- If iron is the major phase, there is enough iron in $\mathrm{Fe}_{1-\mathrm{x}} \mathrm{Ni}_{\mathrm{X}}$ phase to reduce all $\mathrm{Ni}^{2+}$ in the ferrite phase. By repeating steps (a) and (b), the material presents stripes (cf. Fig. 10c).

- If NiZn ferrite is the major phase, the iron present in $\mathrm{Fe}_{1-\mathrm{x}} \mathrm{Ni}_{\mathrm{X}}$ phase reduces only part of the $\mathrm{Ni}^{2+}$ in ferrite phase, forming dots (cf. Fig. 10d).

Redox and diffusion lead to total consumption of the minor phase.

By sintering the composite at a temperature above $800^{\circ} \mathrm{C}$ under low oxygen pressure, $\mathrm{Zn}$ sublimation occurs [17].

Sintering temperature of the Fe ferrite composite can be 


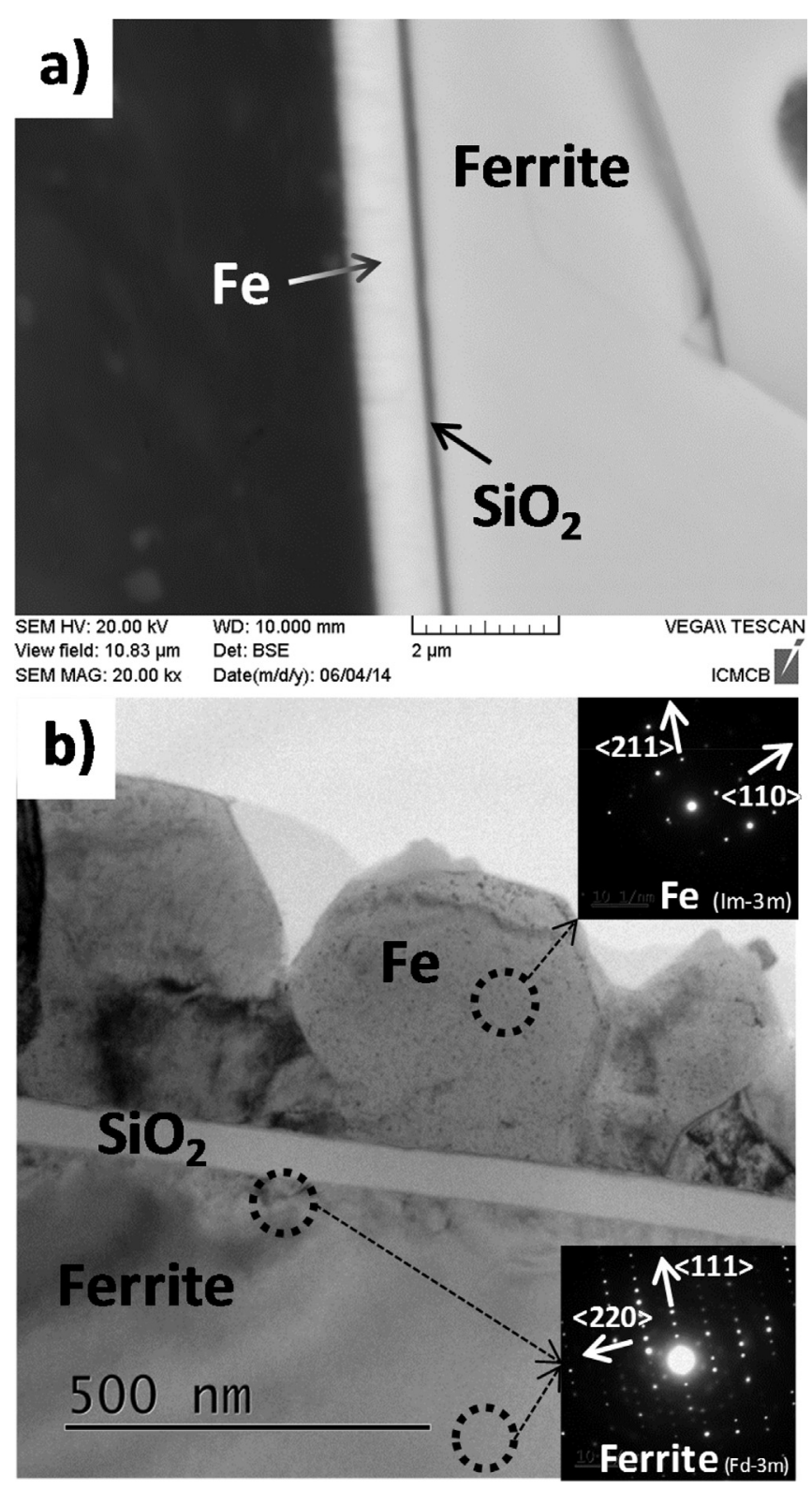

Fig. 8. SEM micrograph (a) and TEM micrograph (b) of $\mathrm{Fe}_{-} \mathrm{SiO}_{2}$-ferrite system heat treated $1 \mathrm{~h}$ at $700{ }^{\circ} \mathrm{C}$ under $\mathrm{N}_{2}$.

enhanced to $800{ }^{\circ} \mathrm{C}$ by adding a $70 \mathrm{~nm} \mathrm{SiO} 2$ interphase. At higher temperatures, $\mathrm{Fe}$ and $\mathrm{SiO}_{2}$ react to form crystallized fayalite. Metallic iron in excess can diffuse into the ferrite substrate and consume part of it. Therefore, the $\mathrm{SiO}_{2}$ layer cannot be used as diffusion barrier for treatment at temperatures above $800{ }^{\circ} \mathrm{C}$ (un der a neutral $\mathrm{N}_{2}$ atmosphere). It should be mentioned that this new architecture of the multi material model, linked with the interca lation of an $\mathrm{SiO}_{2}$ layer, should be confirmed on ferrite material fabricated by powder metallurgy. For the geometry of such mate rial, PVD coating of a powder is not relevant and optimization of a chemical coating on liquid media would be required.

\section{Conclusion}

Fe/NiZn ferrite materials were fabricated and heat treated in order to understand the chemical reactions that can take place between oxide spinel and iron. Three different systems were

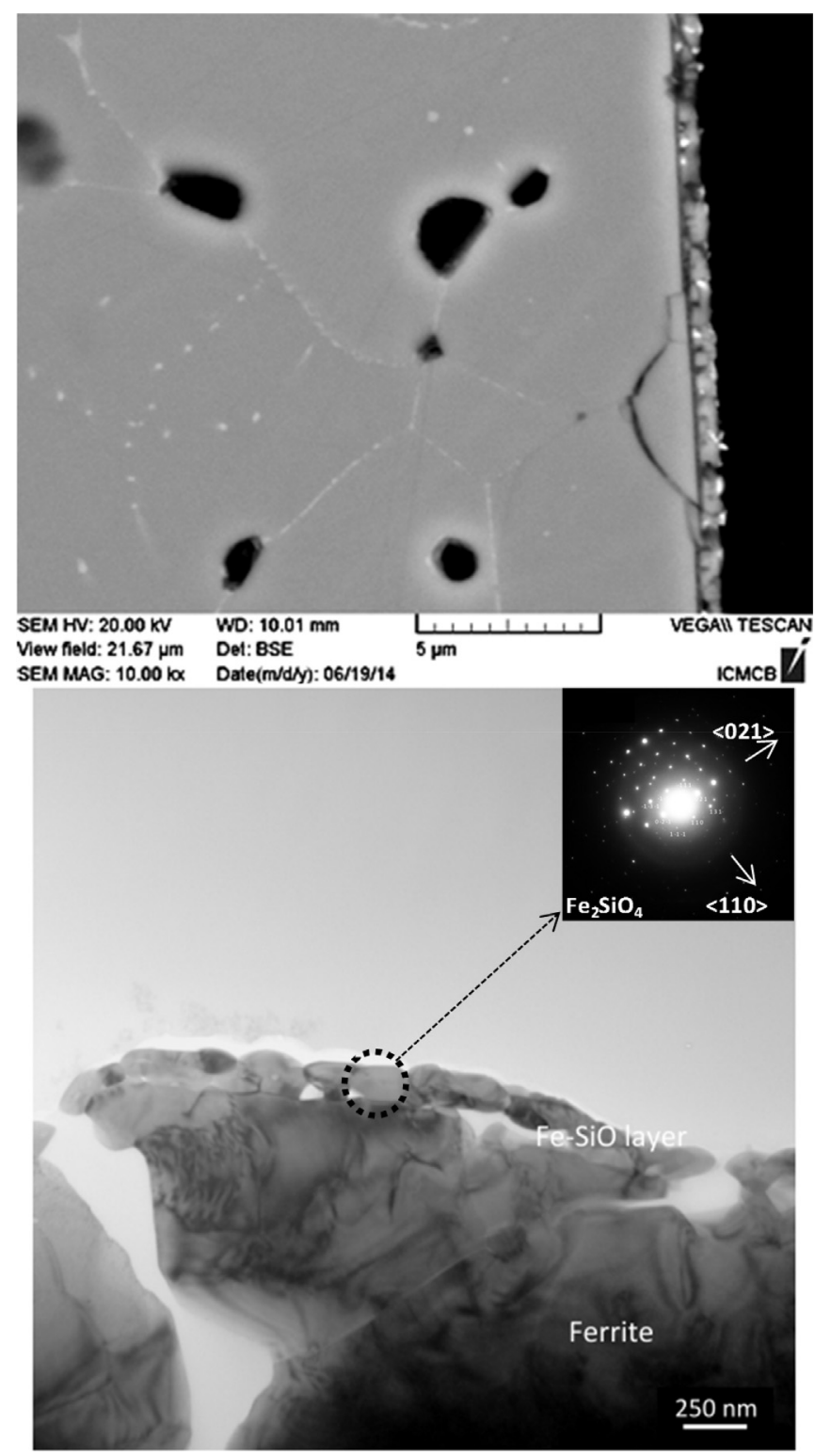

Fig. 9. SEM micrograph (a) and TEM micrograph (b) of Fe-SiO2-ferrite system heat treated $1 \mathrm{~h}$ at $900{ }^{\circ} \mathrm{C}$ under $\mathrm{N}_{2}$.

studied. In the first one, iron films were PVD deposited onto an NiZn ferrite substrate. In the second one, iron/ferrite materials were fabricated using a powder metallurgy process. In the third one, an $\mathrm{SiO}_{2}$ layer was deposited, by PVD, onto the NiZn ferrite substrate, followed by PVD iron deposition in order to form a bulk NiZn ferrite substrate/PVD $\mathrm{SiO}_{2} / \mathrm{PVD}$ Fe system. ATD analyses showed an oxido reduction phenomenon starting at $580{ }^{\circ} \mathrm{C}$. This oxido reduction occurred between $\mathrm{Ni}^{2+}, \mathrm{Fe}^{3+}$ and $\mathrm{Fe}$ at the inter phase between iron and ferrite. This reaction was followed by the disproportionation of $\mathrm{FeNi}$ and $\mathrm{FeO}$ and also by iron diffusion, leading to total consumption of the minor initial phase. The $\mathrm{ZnO}$ phase exhibited good stability during heat treatment, but at tem peratures above $800{ }^{\circ} \mathrm{C}$, sublimation occurred due to low the oxy gen content in the atmosphere. These experimental results obtained with the model materials show that sintering must be done at a temperature lower than $580{ }^{\circ} \mathrm{C}$ in order to avoid the chemical reaction at the NiZn ferrite Fe interface and therefore the creation of complex interphases and finally possible degradation of 


\section{(a) Redox reaction}

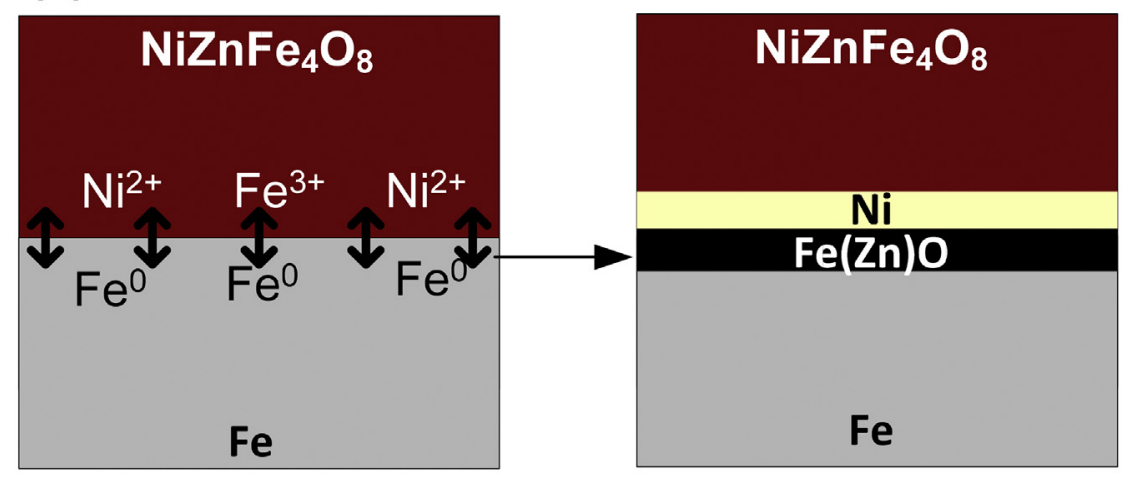

(b) Iron diffusion

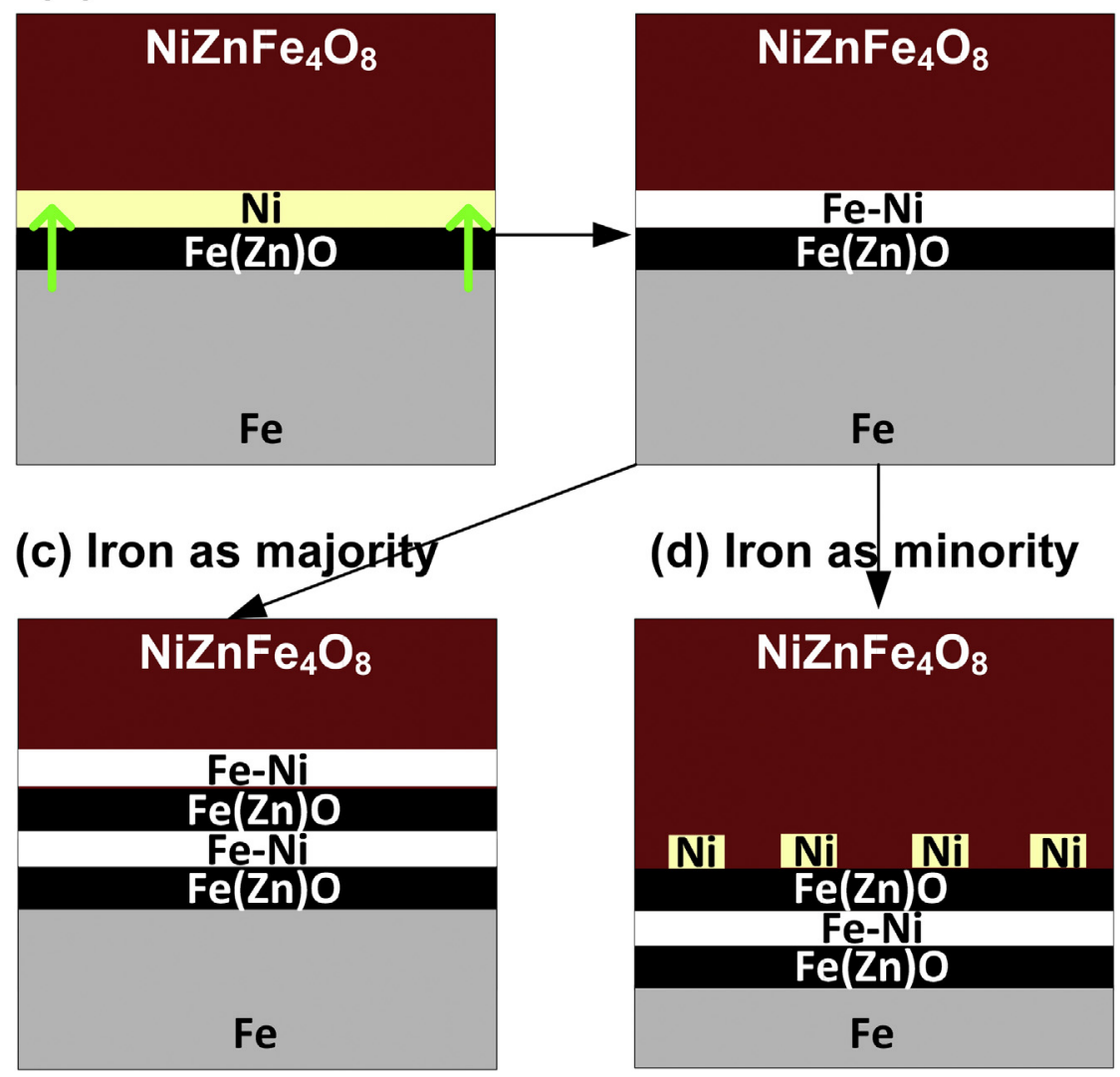

Fig. 10. Scheme of the reaction mechanism between iron and NiZn ferrite.

the physical (namely magnetic) properties of the system. In order to delay this oxido reduction phenomenon in NiZn ferrite Fe systems above $580^{\circ} \mathrm{C}$, an $\mathrm{SiO}_{2}$ thin film was deposited in between these two materials. For this bulk NiZn ferrite substrate/PVD $\mathrm{SiO}_{2} / \mathrm{PVD} \mathrm{Fe}$ model system, the sintering temperature could be increased up to $800{ }^{\circ} \mathrm{C}$ without any interfacial chemical reaction. Above $800{ }^{\circ} \mathrm{C}$, a reaction occurred between iron and the silica layer to form an iron silicate, $\mathrm{Fe}_{2} \mathrm{SiO}_{4}$ (i.e. fayalite).

\section{Conflicts of interest}

The authors whose names are listed immediately below certify that they have no affiliations with or involvement in any organi zation or entity with any financial interest (such as honoraria, educational grants, participation in speakers' bureaus, member ship, employment, consultancies, stock ownership, or other equity interest, and expert testimony or patent licensing arrangements), or non financial interest (such as personal or professional re lationships, affiliations, knowledge or beliefs) in the subject matter or materials discussed in this manuscript.

Author names: Rudy GUICHETEAU, Jean Louis BOBET, Takamichi MIYASAKI, Akira KAWASAKI, YongFeng. LU, Jean François SILVAIN.

\section{References}

[1] T.D. Kefalas, Transformers made of composite magnetic cores: an innovative design approach, Recent Pat. Electr. Eng. 2 (1) (2009) 1 12, http://dx.doi.org 10.2174/1874476110902010001.

[2] T. Ishikawa, S. Sato, S. Takeguchi, A. Matsuo, Design of a DC motor made of soft magnetic composite core by the experimental design method, IEEE Trans. 
Magn. $48 \quad$ (11) (2012) $3132 \quad 3135$, http://dx.doi.org/10.1109/ TMAG.2012.2203333.

[3] L. Yan, J. Wang, Ye Yu, Z. Hao, Q. Liu, F. Li, Broadband and thin microwave absorber of nickel-zinc ferrite/carbonyl iron composite, J. Alloys Compd. 487 (2009) 708 711, http://dx.doi.org/10.1016/j.jallcom.2009.08.051.

[4] C. Wei, X. Shen, F. Song, Y. Zhu, Y. Wang, Double-layer microwave absorber based on nanocrystalline Zn0.5Ni0.5Fe2O4/ $\alpha$-Fe microfibers, Mater. Des. 35 (2012) 363 368, http://dx.doi.org/10.1016/j.matdes.2011.09.018.

[5] A.C. Razzitte, W.G. Fano, S.E. Jacobo, Electrical permittivity of Ni and NiZn ferrite-polymer composites, Phys. B 354 (2004) 28 231, http://dx.doi.org/ 10.1016/j.physb.2004.09.054.

[6] M Doser, DE Floryan, Method of making magnets by polymer-coating magnetic powder, (1976) Patent US3933536.

[7] L.D. Zhang, W.L. Liu, C.L. Xiao, J.S. Yao, Z.P. Fan, X.L. Sun, X. Zhang, L. Wang, X.Q. Wang, Preparation of poly (styrene)-b-poly (acrylic acid) $/ \gamma$-Fe 203 composites, J. Magn. Magn. Mater. 323 (2011) 3087 3091, http://dx.doi.org/ 10.1016/j.jmmm.2011.06.062.

[8] X.G. Liu, D.Y. Geng, H. Meng, W.B. Cui, F. Yang, D.J. Kang, Z.D. Zhang, Microwave absorption properties of FCC-Co/Al2O3 and FCC-Co/Y2O3 nanocapsules, Solid State Commun. 149 (2009) 64 67, http://dx.doi.org/10.1016/ j.ssc.2008.10.015

[9] S. Wu, A. Sun, W. Xu, Q. Zhang, F. Zhai, P. Logan, A.A. Volinsky, Iron-based soft magnetic composites with $\mathrm{Mn}-\mathrm{Zn}$ ferrite nanoparticles coating obtained by sol-gel method, J. Magn. Magn. Mater. 324 (2012) 3899 3905, http:// dx.doi.org/10.1016/j.jmmm.2012.06.042.
[10] J. Xiang, X. Shen, F. Song, M. Liu, G. Zhou, Y. Chu, Fabrication and characterization of Fe-Ni alloy/nickel ferrite composite nanofibers by electrospinning and partial reduction, Mater. Res. Bull. 46 (2011) 258 261, http://dx.doi.org/ 10.1016/j.materresbull.2010.11.004

[11] T.F. Marinca, B.V. Neamtu, F. Popa, V.F. Tarta, P. Pascuta, A.F. Takacs, I. Chicinas, Synthesis and characterization of the NiFe2O4/Ni 3Fe nanocomposite powder and compacts obtained by mechanical milling and spark plasma sintering, Appl. Surf. Sci. 285 (Part A) (2013) 2 9, http://dx.doi.org/10.1016/ j.apsusc.2013.07.145.

[12] H. Su, X. Tang, H. Zhang, Z. Zhong, J. Shen, Sintering dense NiZn ferrite by twostep sintering process, J. Appl. Phys. 109 (7) (2011).

[13] L.S. Darken, Melting points of iron oxides on silica; phase equilibria in the system Fe-Si-O as a function of gas composition and temperature, J. Am. Chem. Soc. 70 (1948) 2051

[14] A. Muan, Phase equilibria in the system $\mathrm{FeO}-\mathrm{Fe}_{2} \mathrm{O}_{3}-\mathrm{SiO}_{2}$, J. Metals (1955) 7.

[15] A.D. Dalvi, W.W. Smeltzer, Diffusion model for oxidation of nickel-iron alloys at $1000{ }^{\circ} \mathrm{C}$, J. Electrochem. Soc. 121 (3) (1974) 386394

[16] C. Gleitzer, Diversity and complexity of the wustite solid solutions I-tentative rationalization of the miscibility data and classification of the wustite ternary fields and of the post saturation reactions, Mater. Res. Bull. 15 (4) (1980) 507 519, http://dx.doi.org/10.1016/0025-5408(80)90058-6.

[17] R. Hansson, P.C. Hayes, E. Jak, Phase equilibria in the Fe-Zn-O system at conditions relevant to zinc sintering and smelting. Inst. Min. Metall., Trans. Sect. C Miner. Process. Extr. Metall. 114 (3) (2004) 141 146, http://dx.doi.org/ 10.1179/037195505X49778. 